\title{
Clinical significance of unexplained elevated maternal serum alpha feto- protein in second trimester of pregnancy
}

\author{
Urmila Karya*, Sweta Kumari, Anupam Rani, Shakun Singh
}

Department of Obstetrics and Gynecology, LLRM Medical College, Meerut, Uttar Pradesh, India

Received: 19 March 2018

Accepted: 21 April 2018

*Correspondence:

Dr. Urmila Karya,

E-mail: urmila726@gmail.com

Copyright: (C) the author(s), publisher and licensee Medip Academy. This is an open-access article distributed under the terms of the Creative Commons Attribution Non-Commercial License, which permits unrestricted non-commercial use, distribution, and reproduction in any medium, provided the original work is properly cited.

\begin{abstract}
Background: Alpha-fetoprotein (AFP) is the major serum protein in the embryonic stage and in the early fetal stage. The aim of this study was to measure maternal serum AFP levels in second trimester between 15-20 weeks of gestation and to determine whether unexplained elevated MSAFP levels is an effective predictor of adverse pregnancy outcome among Indian population.

Methods: This study was a prospective observational study, carried out on 400 pregnant women. Maternal serum alpha-fetoprotein (MSAFP) was measured between 15 and 20 weeks of gestation after excluding congenital malformation or birth defects. MSAFP level was determined by using a radio-immunoassay technique. Women with MSAFP level $>2.0 \mathrm{MoM}$ was considered as abnormal while MSAFP level $\leq 2.0 \mathrm{MoM}$ was considered as normal. All women were followed up till delivery and pregnancy outcomes were noted and compared between two groups.

Results: Women with elevated MSAFP had significantly higher adverse pregnancy outcomes (75.4\%) compared to women with MSAFP $\leq 2.0 \mathrm{MoM}(26.1 \%)$ ( $\mathrm{p}<0.0001$ with relative risk of 2.89, 95\% confidence interval 2.276 -3.667). Conclusions: Unexplained elevated MSAFP has high sensitivity, specificity, positive predictive value and negative predictive value in predicting adverse pregnancy outcomes. It would, therefore be worthwhile screening pregnant women in second trimester for maternal serum alpha-fetoprotein levels as it would help to identify high risk pregnancies and allow close antenatal survillence for better pregnancy outcome.
\end{abstract}

Keywords: Maternal serum alpha-fetoprotein, Maternal and fetal outcome, Pregnancy

\section{INTRODUCTION}

The goal of every obstetrician should be to give the best prenatal care to the fetus to achieve an optimal perinatal outcome. The success of antenatal care is reflected in the reduced maternal mortality, morbidity and fetal salvage. ${ }^{1}$ We are on the threshold of a new and far more important type of antenatal care, and since prevention is always better than cure, it is the role of antenatal care to reduce the need for desperate measures at the time of delivery. ${ }^{2}$ The second half of twentieth century witnessed many advances in maternal care. Following this success, obstetricians turned their attention towards improvement in the health and care of the fetus. Screening in pregnancy is the process of surveying a population of women with markers and defined screening cut-off levels, to identify those at higher risk for a particular disorder. Such women can then be offered further diagnostic tests and appropriate treatment to reduce their risk and/or any complication arising from the disease or condition. Pregnancy is a normal physiological process and any intervention that is offered to the pregnant and expectant mother should have known benefits and should be acceptable to them. Biochemical markers are the building blocks of screening tests. The earliest example of prenatal screening is the use of a single second trimester maternal serum marker, alpha-fetoprotein, to identify pregnancies at high risk of neural tube 
defects. ${ }^{3}$ Its implication extend beyond NTDs screening to detection of other anatomic malformations (gastroschisis, omphalocele etc), multiple pregnancy, Down's syndrome and other aneuploidies and placental disease.

Shortly after the introduction of maternal serum screening for diagnosis of fetal abnormalities, adverse pregnancy outcomes began to be reported after the detection of unexplained isolated elevation of MSAFP. ${ }^{4}$ Unexplained midtrimester MSAFP elevations have been associated with an increased risk for low birth weight, intrauterine growth retardation, premature delivery, placental abruption, intrauterine fetal death, preeclampsia and increased risk of perinatal death. ${ }^{5}$

Measurement of MSAFP level in the second trimester is an important indicator of pregnancy complications and elevated midtrimester MSAFP levels indicate pregnancies at high risk of complications. ${ }^{6}$ Therefore, a proper followup of pregnant women might help to evaluate that risk, warranting increased survillence. Hence present study was an endeavour to find out correlation between second trimester MSAFP levels and adverse pregnancy outcomes.

\section{METHODS}

It was a prospective observational study conducted in L.L.R.M Medical College and associated S.V.B.P. Hospital, Meerut, over a period of one and half year from May2016 to October 2017. The study protocol was approved by Institutional ethical committee. Total of 400 women of age group 18-35 years with singleton pregnancy between 15-20 weeks of gestation, attending antinatal clinic of our institution, were enrolled for the study after observing the inclusion and exclusion criteria.

\section{Inclusion criteria}

Inclusion criteria were pregnant women of age group 1835 years; singleton pregnancy; gestational age of 15-20 weeks based on reliable last menstrual period (LMP) and / or a dating scan in the first trimester; women with normal level II USG Scan.

\section{Exclusion criteria}

Exclusion criteria were multiple pregnancy; smoker, women with known hypertensive disorders (Essential hypertension); BMI >30; women with diagnosed structural abnormalities in fetus e.g. open neural tube defects, abdominal wall defects, cystic hygroma etc; women with diagnosed fetal chromosomal abnormalities e.g. trisomies 18-21, etc.; intra uterine fetal demise; placental abnormalities such as placental tumours (e.g. chorioangioma), placental infarction, cystic changes in placenta.

A detailed history of present pregnancy including duration of gestation, any associated complain, past history of any medical illness was taken as per working proforma. Gestational age was confirmed by the date of last menstruation and by the CRL measured by ultrasonography between $8^{\text {th }}$ and $12^{\text {th }}$ gestational weeks. Any congenital anomaly or birth defect in the foetus was ruled out by the obstetric level II ultrasound scan. All women were counselled about importance of maternal serum alpha fetoprotein screening. After obtaining informed and written consent for enrollment in study, a fresh venous blood sample (3-5 $\mathrm{ml}$ in amount) was collected under aseptic precautions. Measurement of MSAFP was done by RADIOIMMUNOASSAY technique done in a single laboratory and by an experienced pathologist (as median is fixed for each laboratory). MSAFP level >2 mom were considered as abnormal. All the pregnancies were followed up regularly till delivery for maternal and fetal outcome. Maternal outcome in terms of pre-eclampsia / eclampsia, placental abruption, PPROM, preterm labour, oligohydraminos were noted. Fetal outcome in terms of low birth weight, Intra uterine growth retardation, still birth, IUD and perinatal morbidity (birth asphyxia, low apgar score, neonatal intensive care unit admissions) were noted. The gathered data was entered in Microsoft Excel. Descriptive and inferential statistical analysis had been carried out to explore the association between MSAFP level with the other variables under study like, Pre-eclampsia, eclampsia, preterm labour, olighydramnios etc. Chisquare / fisher exact test has been used to test the statistical significance. Sensitivity, specificity, positive predictive value, negative predictive value have been calculated for all the important associations. Level of significance had been set to $5 \%$ and hence the p-value of $<0.05$ had been considered as significant.

\section{RESULTS}

The total study population was 400 pregnant women at 15 to 20 weeks of gestation. They were divided into two groups according to their MSAFP level.

\section{- Group I: Women with MSAFP level >2 MoM \\ - Group II: Women with MSAFP level $\leq 2 \mathrm{MoM}$}

Out of 400 recruited women, 360 were followed up till delivery while 40 were lost to follow up. Out of 360 subjects $130(36.1 \%)$ had MSAFP level >2 MoM while $230(63.9 \%)$ women had MSAFP level $\leq 2$ MoM. The epidemiological characteristics of the two study groups did not show statistically significant differences (Table1). In group I $16.9 \%$ women had preterm delivery compared to only $5.2 \%$ in group II ( $\mathrm{p}=0.0002$, Relative risk -3.244 with $95 \%$ CI-1.66 to 6.337). Elevated MSAFP level in predicting preterm delivery had moderate sensitivity and specificity i.e. $64.17 \%$ and $66.87 \%$ respectively. Positive predictive value and negative predictive value was $16.92 \%$ and $94.78 \%$ respectively. Oligohydramnios was observed in $15.38 \%$ pregnancies in group I and $7.8 \%$ in group II (P value- 0.024, relative risk-1.966 with 95\% CI1.08 to 3.58$)$. Sensitivity, specificity, positive predictive 
value, negative predictive value of test in predicting oligohydramnios was $52.68 \%, 65.84 \%, 15.8 \%$ and $92.17 \%$ respevtively. The incidence of pre-eclampsia in group with elevated MSAFP level (MSAFP level >2 MoM) was $20 \%$ whereas only $6 \%$ in group II developed pre-eclampsia $(\mathrm{p}=0.001$, Relative risk- 2.477 with $95 \%$ CI-1.133 to 5.417). Elevated MSAFP levels in predicting pre-eclampsia had moderate sensitivity and specificity, $65 \%$ and $67.5 \%$ respectively. It had very high negative predictive value i.e. $93.9 \%$. Positive predictive value was $20 \%$. Placental abruption occurred in $6.15 \%$ pregnant women in group I whereas only $0.9 \%$ in group II $(\mathrm{p}=0.003$, relative risk-7.077 with $95 \% \mathrm{CI}-1.133$ to 5.417).Elevated MSAFP levels in predicting placental abruption had high sensitivity i.e. $80 \%$, very high negative predictive value i.e.99.13\%.The incidence of PPROM in group I was $6.2 \%$ whereas the incidence was only $1.7 \%$ in group II $(\mathrm{p}=0.032$, relative risk $=3.54$ with 95\% CI-1.08 to 11.5). Elevated MSAFP levels in predicting PPROM had moderate sensitivity and specificity i.e. $66.67 \%$ and $64.94 \%$ respectively and very high negative predictive value i.e. $98.26 \%$. Positive predictive value was $6.15 \% .10 .77 \%$ fetus had IUGR in group I compared to only $4.3 \%$ in group II (P value 0.018 , Relative risk - 2.477 with $95 \%$ CI-1.135 to 5.417 ). Elevated MSAFP levels in predicting IUGR had moderate sensitivity and specificity i.e. $58.33 \%$ and $65.48 \%$ respectively. It had very high negative predictive value i.e. $95.65 \%$, positive predictive value was $10.77 \%$ (Table 2, Table 3). In group I 78.4\% women had vaginal delivery and in group II $91.3 \%$ women had vaginal delivery i.e. more number of women in group I were delivered by caesarean section $28 \%$ versus $8.7 \%$ in group II (p value-0.02). Need for induction was more in group I $(16.9 \%)$ than in group II $(5.2 \%)$. Adverse neonatal outcomes were seen more in group I with compared to group II in terms of poor apgar score at $1 \mathrm{~min}(13.8 \%$ vs $2.6 \%)$ and $5 \min (15.4 \%$ vs $3.5 \%)$, still birth $(6.15 \%$ vs $1.7 \%)$, IUFD( $3.1 \%$ vs $0.9 \%)$,early neonatal death( $10.6 \%$ vs $2.6 \%$ ). Adverse pregnancy outcomes were more in group I (MSAFP level > 2MoM) i.e.75.4\% as compared to group II (MSAFP level $\leq 2 \mathrm{MoM}$ ) i.e. $26.1 \%$. Elevated MSAFP levels had high sensitivity, specificity, PPV, NPV in predicting adverse pregnancy outcome.

Table 1: Epidemiological characteristics of the two study groups.

\begin{tabular}{|c|c|c|c|}
\hline Variable & $\begin{array}{l}\text { Group I } \\
\text { MSAFP level > } 2 \text { MoM }\end{array}$ & $\begin{array}{l}\text { Group II } \\
\text { MSAFP level } \leq 2 \text { MoM }\end{array}$ & P value \\
\hline Mean age $($ mean \pm SD $)$ & $24.23 \pm 2.62$ & $24.18 \pm 3.02$ & 0.87 \\
\hline Mean BMI & $22.12 \pm 1.4$ & $22.11 \pm 1.2$ & 0.9 \\
\hline Primigravida & $61.5 \%$ & $69.6 \%$ & 0.13 \\
\hline Multigravida & $38.5 \%$ & $30.4 \%$ & 0.13 \\
\hline $\begin{array}{l}\text { Mean gestational age at time of MSAFP } \\
\text { screening (mean } \pm \text { SD) }\end{array}$ & $16.34 \pm 0.32$ & $16.41 \pm 0.35$ & 0.06 \\
\hline
\end{tabular}

Table 2: Summary of results for each outcome.

\begin{tabular}{|c|c|c|c|c|c|c|c|}
\hline \multirow{2}{*}{$\begin{array}{l}\text { Pregnancy } \\
\text { outcome }\end{array}$} & \multicolumn{2}{|c|}{$\begin{array}{l}\text { Group I MSAFP level } \\
>2 \text { MoM } n=130\end{array}$} & \multicolumn{2}{|c|}{$\begin{array}{l}\text { Group II MSAFP level } \\
\leq 2 \text { MoM } n=230\end{array}$} & \multirow{2}{*}{ P value } & \multirow{2}{*}{$\mathbf{R R}$} & \multirow{2}{*}{$95 \% \mathrm{CI}$} \\
\hline & $\mathbf{n}$ & $\%$ & $\mathbf{n}$ & $\%$ & & & \\
\hline Preterm delivery & 22 & 16.92 & 12 & 5.2 & 0.0002 & 3.244 & $1.66-6.337$ \\
\hline Pre-eclampsia & 26 & 20 & 14 & 6 & 0.001 & 2.477 & $1.133-5.417$ \\
\hline Oligohydramnios & 20 & 15.38 & 18 & 7.8 & 0.024 & 1.966 & $1.08-3.58$ \\
\hline IUGR & 14 & 10.77 & 10 & 4.3 & 0.018 & 2.477 & $1.133-5.417$ \\
\hline Placental abruption & 8 & 6.2 & 2 & 0.9 & 0.003 & 7.077 & $1.526-32.83$ \\
\hline PPROM & 8 & 6.2 & 4 & 1.7 & 0.032 & 3.54 & $1.08-11.5$ \\
\hline All complication & 98 & 75.4 & 60 & 26.1 & $<0.0001$ & 2.890 & $2.276-3.669$ \\
\hline
\end{tabular}

Table 3: Diagnostic ability of MSAFP levels in predicting adverse pregnancy outcome.

\begin{tabular}{|lllll|}
\hline Outcome & Sensitivity $(\%)$ & Specificity $(\%)$ & PPV $(\%)$ & NPV $(\%)$ \\
\hline Preterm delivery & 64.71 & 66.87 & 16.92 & 94.78 \\
\hline Pre-eclampsia & 65 & 67.5 & 20 & 93.9 \\
\hline Oligohydramnios & 52.63 & 65.84 & 15.38 & 92.17 \\
\hline IUGR & 58.33 & 65.48 & 10.77 & 95.65 \\
\hline Placental abruption & 80 & 65.15 & 6.15 & 99.13 \\
\hline PPROM & 66.67 & 64.94 & 6.15 & 98.26 \\
\hline Adverse pregnancy outcome & 62.03 & 84.16 & 75.38 & 73.91 \\
\hline
\end{tabular}




\section{DISCUSSION}

In systemic supervision of pregnancy ideally a pregnant women should be seen once in the first trimester. But in developing countries because of transport problems, financial restraints or inability to spare the time to visit the clinic, first trimester screening is still not routine and thus second trimester biochemical screening has an important role in such women. One of the important second trimester markers for biochemical screening is MSAFP. The present study was carried out to measure the MSAFP levels in second trimester and to correlate unexplained elevated MSAFP levels with adverse pregnancy outcome. We evaluated pregnancy outcome in women with unexplained elevated MSAFP level > MoM in second trimester (excluding any possible causes for MSAFP elevation) and compared their pregnancy outcome with the women who had normal MSAFP levels $(\leq 2 \mathrm{MoM})$. Women in both the groups (Group I-MSAFP level $>2 \mathrm{MoM}$ and Group II-MSAFP level $\leq 2 \mathrm{MoM}$ ) were comparable in terms of their epidemiological characteristics. To determine the optimal AFP cut-off value, Yuan et $\mathrm{al}^{7}$ carried out a systematic study of the relationship between elevated second trimester (16 to 20 weeks) MSAFP in the general population and preterm delivery.

The study examined a total of 207,135 women in 24 studies published between the years 1991 and 2007 including 14 population-based studies and 10 comparative case-control studies. Fourteen of the studies used 2.0 MoM as the elevated AFP level, while eight studies used 2.5 MoM as the cut-off value. The most effective thresholds were 2.0 multiples of the median (MoM) for alpha-fetoprotein (AFP) resulting in a positive likelihood ratio (LR) of 2.36 and a negative likelihood ratio of 0.96 . In our study for evaluating the association between unexplained MSAFP elevation and pregnancy complications, we used the cut-off value for unexplained MSAFP as $>2$ MoM. The results of our study showed that unexplained MSAFP level >2 MoM in the second trimester of pregnancy ( 15 to 20 weeks) was related with maternal, fetal and neonatal complications.

In our study preterm delivery in the group I was $16.92 \%$ as opposed to $5.23 \%$ in group II. In study done by T.S.U Kiran et al preterm delivery rate was $9.4 \%$ in women with MSAFP level $>2$ MoM whereas only $3.35 \%$ in women with MSAFP level $\leq 2$ MoM. $^{8}$ Salvatore et al observed in their study that among women with high levels of MSAFP ( $\geq 2.5 \mathrm{MoM}), 21.4 \%$ had preterm births, compared to $4.5 \%$ of women with low MSAFP levels. ${ }^{9}$ Dehgani- Firouzabadi et al also confirmed raised MSAFP levels were associated with preterm labour $(\mathrm{p}=0.021){ }^{10}$ Rebecca et al reported that the rate of preterm delivery in pregnancies with MSAFP level > 2 MOM was $18 \%$ compared to $7 \%$ when MSAFP level is $\leq 2.0 \mathrm{MOM}$ ( $\mathrm{p}=$ $0.005)$ with a odds ratio of 2.9 (95\% CI- 1.3 to 6.4$).{ }^{11}$ Bhattacharjee et al in a prospective observational study found that the rate of preterm birth was significantly higher in women with high MSAFP (20\% vs. 5.23\%) with a relative risk of 3.822 (95\% CI-1.467 to $9.959 .{ }^{12} \mathrm{In}$ our study, sensitivity, specificity, PPV, NPV of test was $64.17 \%, 66.87 \%, 16.92 \%, 94.78 \%$ respectively. Similar results were seen in study conducted by Kiran et al (sensitivity-8.4\%, specificity-96.4\%, PPV-9.3\%, NPV$96 \%$ ), Allen et al (sensitivity-16\%, specificity-94\%, PPV$18 \%$, NPV-93\%), Basbug D et al (sensitivity-44.6\%, specificity-87.3\%, PPV-17.1\%, NPV-96.4\%). ${ }^{13}$

In the present study pre-eclampsia occurred in $20 \%$ women in the group with elevated MSAFP (>2 MoM) compared to $6 \%$ women in the group with MSAFP level $\leq 2$ MoM. Other studies had also shown the strong correlation. Allen et al reported that $24.4 \%$ of women with elevated MSAFP levels (>2 MoM) developed preeclampsia compared to only $4.6 \%$ of the women with normal MSAFP $(\leq 2 \mathrm{MoM}) .{ }^{11}$

Williams et al found a significant association between elevated MSAFP and pre- eclampsia, adjusted risk ratio being 3.8 (95\% CI-1.6 to 9.1). ${ }^{14}$ Walters et al also reported that more women with elevated MSAFP developed pre-eclampsia compared to women with normal MSAFP (13\% vs $1 \%) .{ }^{15}$ Present results concluded that in prediction of pre-eclampsia sensitivity, specificity, PPV, NPV of test was $65 \%, 67.5 \%, 20 \%, 93.9 \%$ respectively. Similar results were seen in study conducted by, Allen et al (sensitivity: 24\%, specificity: 94\%, PPV: 20\%, NPV: 95\%), Basbug D et al (sensitivity-17.9\%, specificity-85.6\%, PPV-2.9\%, NPV-97.7\%). ${ }^{13}$ In view of our study results, we would recommend to check the blood pressure and urinalysis more frequently in the second half of pregnancy in women with a raised MSAFP level, as these women are at significantly increased risk of developing preeclampsia.

The diagnosis of oligohydramnios was made when the maximum vertical pocket of liquor was less than $2 \mathrm{~cm}$ or when amniotic fluid index (AFI) was less than $5 \mathrm{~cm}$. In the present study, we observed oligohydramnios in $15.38 \%$ women in group I compared to $7.8 \%$ women in group II. Basbug D et al also concluded that in women with elevated MSAFP values $\geq 2 \mathrm{MoM}$, olighydramnios developed in $31.3 \%$ women compared to only $13.4 \%$ in women with MSAFP values <2 MoM. ${ }^{13}$ In the present study for prediction of oligohydramnios, test sensitivity specificity, PPV, NPV was 52.63\%, 65.84\%, $15.38 \%$, $92.17 \%$ respectively. Similar results was seen in study conducted by, Basbug $\mathrm{D}$ et al (sensitivity-31.3\%, specificity-86.6\%, PPV-12.4\%, NPV-95.4\%). ${ }^{13}$

IUGR was developed in $10.77 \%$ women in group I compared to $4.3 \%$ in group II. Basbug D et al reported high incidence $(40.7 \%$ vs $13.1 \%)$ of IUGR in women with MSAFP level $>2$ MoM. ${ }^{13}$ Bhattacharjee et al in a prospective observational study found that IUGR was significantly higher in women with high MSAFP (6\% vs. $3 \%$ ) with a relative risk of 3.3 (95\% CI-1.4 to 7.8$).{ }^{12} \mathrm{~S}$. Anfuso et al also reported that IUGR was more in women 
with elevated MSAFP level (8.3\% vs. $2 \%)$ with a relative risk of 5.9 (95\% CI-1.5 to 23.6). ${ }^{9}$ Diagnostic ability of test in our study for predicting IUGR was $58.33 \%$ sensitive, $65.48 \%$ specific with positive predictive value of $10.77 \%$ and negative predictive value of $95.65 \%$. Similar results were seen in study conducted by Allen $\mathrm{R}$ et al (sensitivity-26\%, specificity-96\%, PPV-42\%, NPV$91 \%$ ), Derya Basbug et al (sensitivity-40.7\%, specificity86.9\%, PPV-14.1\%, NPV-96.5\%). ${ }^{11,1}$ Hence women with MSAFP greater than $2.0 \mathrm{MoM}$ should be offered increased antenatal surveillance in the form of ultrasound scans for growth for early detection and management of IUGR.

Our study showed placental abruption was more in group I compared to group II (6.15\% vs $0.9 \%)$. Salvatore et al also observed in their study that among women with high levels of MSAFP developed placental abruption compared to women with normal MSAFP levels (7.1\% vs $2 \%) .{ }^{9}$ Our result was also in agreement with those of Williams et al (4\% vs. $3.8 \%$, OR-4.8). ${ }^{14}$ Diagnostic ability of test for predicting placental abruption in our study was $80 \%$ sensitive, $65.15 \%$ specific with positive predictive value of $6.15 \%$, negative predictive value of $99.13 \%$.

In our study, PPROM occurred in $6.2 \%$ women in group I compared to $1.7 \%$ women in group II. Salvatore et al also observed in their study that among women with high levels of MSAFP 7.1\% had PPROM compared to only in $0.5 \%$ of women with normal MSAFP levels (p-value0.001 , OR-15.2,95\% CI-1.8 to 128.6). Basbug D et $\mathrm{al}^{13}$ also reported in their study that women with raised MSAFP level $(\geq 2$ MoM) had higher incidence of PPROM compared to women with MSAFP level <2MoM (41.9\% vs $13.4 \%$, p value-0.001, OR-4.55, 95\% CI-2.186 to 9.469$)$. In the present study for prediction of PPROM sensitivity, specificity, PPV, NPV of test was $66.67 \%, 64.94 \%, 6.15 \%, 98.26 \%$ respectively. Similar results were seen in study conducted by Basbug D et $\mathrm{al}^{13}$ (sensitivity-41.9\%, specificity-86.3\%, PPV-7.6\%, NPV$98.2 \%)$.

Adverse neonatal outcomes were seen more in group I with compared to group II in terms of poor Apgar score at $1 \mathrm{~min}(13.8 \%$ vs $2.6 \%)$ and $5 \mathrm{~min}(15.4 \%$ vs $3.5 \%)$, still birth (6.15\% vs $1.7 \%)$, IUFD (3.1\% vs $0.9 \%)$, early neonatal death $(10.6 \%$ vs $2.6 \%)$.

A strong association between second trimester elevated MSAFP level and adverse pregnancy outcome (preterm birth, preeclampsia, oligohydramnios, IUGR, placentalabruption, PPROM, IUFD, stillbirth, neonatal death) was found in our study ( $p$ value <0.0001). DehghaniFirouzabadi R et al, Basbag D et al, Kiran TSU et al, Bhattacharjee AK et al, Anfuso $\mathrm{S}$ et al also revealed significant association between unexplained elevated MSAFP level in second trimester with adverse pregnancy outcomes. ${ }^{8-10,12,13}$ Diagnostic ability of this screening test in predicting adverse pregnancy outcomes in terms of sensitivity (62.03\%), specificity (84.16\%), positive predictive value $(75.38 \%)$ and negative predictive value $(73.91 \%)$ were in agreement with Ozturk $\mathrm{H}$ et al (sensitivity-21\%, specificity-91.5\%, PPV-55.26\%, NPV$69.85 \%$ ), Allen et al (sensitivity-24\%, specificity-96\%, PPV-52\%, NPV-88\%). ${ }^{11,15}$ Boyd et al proposed that 2 nd trimester AFP elevation in a normally formed fetus can be attributed mainly to changes in the placenta which has the property of responding to an adverse environment by increasing its surface of exchange. ${ }^{16}$ Brazerol et al reported that the explanation for the association between elevated maternal serum alpha fetoprotein and adverse pregnancy outcome is not clear, but is probably a marker of placental dysfunction, including partial placental abruption, fetomaternal bleeding and abnormal implantation. ${ }^{17}$ Yaron et al also claimed that changes in the serum levels of AFP might be explained by underlying modification in the function and structure of placenta. $^{18}$

\section{CONCLUSION}

Women with unexplained elevated Maternal Serum Alpha-Fetoprotein level >2.0 MoM measured between 15 to 20 weeks of gestation do have an increased risk of adverse pregnancy outcome (both maternal and fetal) compared to women with MSAFP level $\leq 2.0 \mathrm{MoM}$. The results are not only statistically, but also clinically significant and are in agreement with most reports published so far. It would therefore be worthwhile screening pregnant women in second trimester for maternal serum alpha-fetoprotein levels as it would help to identify high risk pregnancies, allow close antenatal surveillance for a better pregnancy outcome.

Present study shows, unexplained elevated MSAFP level has high sensitivity, specificity, positive predictive value and negative predictive value in predicting adverse pregnancy outcome. Its measurement is easily accessible and safe. Further it is found to be one of the cost effective and non-invasive screening method. But till now no definitive follow up and treatment plans have been practised for high risk women. So, we recommend to educate women about the signs and symptoms of complications and besides biochemical screening to undergo more frequent antenatal checkups and testing by other modalities.

Funding: No funding sources

Conflict of interest: None declared

Ethical approval: The study was approved by the Institutional Ethics Committee

\section{REFERENCES}

1. Padubidri V. Ela Anand Text book of obstetrics II ed. 2006;8:53-62.

2. Evans MI, Galen RS, Drugan A. Biochemical Screening. In Evans MI, Jonson MP, Yaron Y, 
Drugan A (eds): Prenatal Diagnosis. McGraw Hill Publishing Co, NY; 2006: 277-288.

3. Arias F, Bhide A, Arulkumaran S, Damania K, Daftary S. Practical Guide to High-Risk Pregnancy \& Delivery. 3rd ed, Chapter 2, Elsevier; 2008: 40.

4. Harper ME, Dugaiczyk A. Linkage of the evolutionarily-related serum albumin and afetoprotein genes within q11-22 of human chromosome 4. Am J Hum Genet. 1983;35:565-72.

5. Waller DK, Lustig LS, Cunningham G, Feuchtbaum L, Hook E; The association between maternal serum alpha-fetoprotein and preterm birth, small for gestational age infants, preeclampsia and placental complications. Obstet Gynecol. 1996;88:816-22.

6. Burton BK. Outcome of pregnancy in patients with unexplained elevated or low levels of AFP. Obstet Gynecol. 1988;72:709-71.

7. Yuan W, Chen L, Bernal AL. Is elevated maternal serum alpha-fetoprotein in the second trimester of pregnancy associated with increased preterm birth risk? A systematic review and meta-analysis. Eur J Obstet Gynecol Reprod Biol. 2009;145(1):57-64.

8. Kiran TSU, Bethel J, Bhal PS. Correlation of abnormal second trimester maternal serum alphafetoprotein (MSAFP) levels and adverse pregnancy outcome. J Obstet Gynaecol. 2005;25(3):253-6.

9. Anfuso S, Soncini E, Bonelli P, Piantelli G, Gramellini D. Second-trimester maternal serum alpha-fetoprotein elevation and its association with adverse maternal/fetal outcome: ten years experience. Acta Biomed. 2007;78:214-9.

10. Dehghani-Firouzabadi R, Tayebi N, Ghasemi N, Tahmasbi Z. The association between secondtrimester maternal serum alpha-fetoprotein in 14-22 weeks and adverse pregnancy outcome. Acta Med Iran. 2010;48:234-8.

11. Rebecca A, Shemoon M, Luxmi V. The relationship between second trimester alpha-fetoprotein levels and adverse pregnancy outcome. Open J Obstetr Gynecol. 2013;3:262-6.

12. Bhattacharjee AK, Deka G, Begum F, Bayan M. Study on Elevated Maternal Serum AlphaFetoprotein in Second Trimester as a screening test for predicting adverse pregnancy outcome. The New Indian J OBGYN. 2016;3(1):20-3.

13. Başbuğ D, Başbuğ A, Gülerman C. Is unexplained elevated maternal serum alpha-fetoprotein still important predictor for adverse pregnancy outcome? Ginekologia Polska. 2017; 88(6):325-30.

14. Williams MA, Hickok DE, Zingheim RW, Luthy DA, Kimelman J, Nyberg DA, et al. Elevated maternal serum alpha-fetoprotein levels and midtrimester placental abnormalities in relation to subsequent pregnancy. Am J Obstet Gynecol. 1992;167(4 Pt 1):1032-7.

15. Ozturk H, Erkaya S, Altınbaş S, Karadağ B, Tonyalı $\mathrm{NV}$, Ozkan D. The role of unexplained high serum alpha-fetoprotein (AFP) and human chorionic gonadotropin (hCG) levels in the second trimester to determine poor obstetric outcomes.J Turk Soc Obstet Gynecol. 2014;3:142-7.

16. Boyd, P. and Keeling, J. (1986) Raised maternal serum alpha- fetoprotein in the absence of fetal abnormality-placental findings. A quantitative morphometric study. Prenatal Diagnosis. 1986;6:369-73.

17. Krause $T$, Christens $P$, Wohlfahrt J, Lei U, Westergaard T, Norgaard-Pedersen B, et al. (2001) Second trimester maternal serum alpha-fetoprotein and risk of adverse pregnancy outcome. Obstetrics and Gynecol. 2001;97:277-82.

18. Yaron Y, Cherry M, Kramer RL, O’Brien JE, Hallak M, Johnson MP, et al. Second trimester maternal serum marker screening: maternal serum afetoprotein, b-human chorionic gonadotropin, estriol, and their various combinations as predictors of pregnancy outcome. Am J Obstet Gynecol. 1999;181(4):968-74.

Cite this article as: Karya U, Kumari S, Rani A, Singh S. Clinical significance of unexplained elevated maternal serum alpha feto-protein in second trimester of pregnancy. Int J Reprod Contracept Obstet Gynecol 2018;7:2245-50. 